\title{
Effect of Flow Induced Acoustic Resonance on Vortex Shedding from Staggered Tube Banks*
}

\author{
Hiromitsu HAMAKAWA** $^{* *}$, Tohru FUKANO***, Eiichi NISHIDA**** and Hideki ISHIDA ${ }^{\dagger}$ \\ In the present paper, attention was focused on the relation between vortex shedding phe- \\ nomena and acoustic resonance in staggered tube banks. As a result, three types of vortex \\ shedding were found with different Strouhal numbers $\left(S_{t}\right), 0.29,0.22$, and 0.19 , in cases with- \\ out resonance. When resonance was generated at the natural frequency of the duct, $342.5 \mathrm{~Hz}$, \\ at a gap velocity of $39.2 \mathrm{~m} / \mathrm{s}$, two types of vortex shedding were found with different fre- \\ quencies, mainly about $342.5 \mathrm{~Hz}\left(S_{t}=0.29\right)$ and $262.5 \mathrm{~Hz}\left(S_{t}=0.22\right)$, inside the tube banks. \\ The velocity fluctuation and periodicity of the vortex shedding were the most intense in the \\ wake of the second row of tube banks. A short baffle plates was effective for preventing the \\ generation of acoustic resonance of the transverse mode if it was installed at the correct place \\ where velocity fluctuation and periodicity of vortex shedding were most intense.
}

Key Words: Vortex, Flow Induced Vibration, Noise, Heat Exchanger, Acoustic Resonance, Strouhal Number, Tube Banks, Staggered Arrangement

\section{Introduction}

In a heat exchanger, such as a boiler for commercial use, acoustic resonant noise is occasionally generated in the duct when gas flows laterally to the axis of the tube banks. Flow induced vibration and noise in heat exchanger can be found in the review paper ${ }^{(1)-(3)}$. It is generally known that the excitation mechanisms causing flow induced vibration of tube banks in cross flow are generally classified as vortex shedding, acoustic resonance, turbulent buffeting and fluidelastic ${ }^{(1),(4),(5)}$.

The acoustic resonant noise generated from heat exchangers is usually caused by the resonance of the structure of the boiler and vortex shedding from tube banks. Many studies have been published on the excitation mech-

* Received 6th September, 2004 (No. 04-4197)

** Department of Mechanical Engineering, Oita University, 700 Dannoharu, Oita 870-1192, Japan.

E-mail: hamakawa@cc.oita-u.ac.jp

*** Department of Environmental Symbiosis Engineering, Kurume Institute of Technology, 2228 Kamitsu-machi, Kurume 830-0052, Japan.

E-mail: fukanot@cc.kurume-it.ac.jp

**** Department of Mechanical Engineering, Shonan Institute of Technology, 1-1-25 Tujido Nishi Kaigan, Fujisawa 251-8511, Japan. E-mail: nishida@mech.shonan-it.ac.jp

† Mitsui Engineering \& Shipbuilding Co., Ltd., 5-6-4 Tukiji, Cyuou-ku, Tokyo 104-8439, Japan anisms causing acoustic resonance in tube banks in cross flow $^{(6)-(9)}$. They has shown clearly that the cause of acoustic resonance was periodic vortex formation in the space between the tubes. Vortex shedding can cause acoustic resonance of the tube banks containers.

Recently, many researchers have reported on the phenomena of vortex shedding in staggered tube banks ${ }^{(10)-(15)}$. They found two types of vortex shedding with different Strouhal numbers. The higher number was attributed to alternating vortex shedding from the first row tubes, and the lower one was regarded as the result of alternating vortex shedding from the second row tubes. More recently, three types of vortex shedding with different Strouhal numbers have been observed by A. Oengören and S. Ziada ${ }^{(16)}$. The high frequency component associated with alternating vortex shedding from the first rows, a low frequency component due to alternating vortex shedding from the rear rows, and the third component was attributed to nonlinear interaction between the high and low frequency components.

On the other hand, some studies have been published on the effects of an acoustic wave on vortex shedding from a circular cylinder ${ }^{(17)-(20)}$. According to those papers, when loud sound was applied the frequency of vortex shedding locked at the frequency of the applied sound, the vortex shedding correlated with the sound and the amplitude of velocity fluctuation of vortex shedding increased. Therefore, it was believed that if the vortex shed- 
ding frequency approached the resonant frequency of the duct in tube banks, then acoustic resonance would develop. The resonance strongly enhances the vortex shedding by increasing its axial correlation length and by locking the shedding frequency to the natural resonant frequency. However, there are few studies on the vortexresonance interaction mechanism in tube banks ${ }^{(21)-(23)}$. Effect of acoustic resonance on vortex shedding from staggered tube banks have not been cleared.

The purpose of the present investigation was to clarify experimentally effect of acoustic resonance of transverse mode on vortex shedding from the staggered tube banks. The relation was examined through vortex shedding characteristics in cases with and without acoustic resonance. Finally, a method of preventing the acoustic resonance by using baffle plates will be discussed.

\section{Experimental Apparatus and Procedure}

The schematic view of the experimental apparatus used in the present experiment is shown in Fig. 1. The wind tunnel was an open-circuit with the blower located upstream of the test section. The test section was a rectangular duct $1.6 \mathrm{~m}$ long, $0.5 \mathrm{~m}$ wide, and $0.5 \mathrm{~m}$ high. The tube banks were installed in the test section so that the front of the banks was $130 \mathrm{~mm}$ downstream of the nozzle exit.

The staggered tube array is defined in Fig. 2. The tube pitch in the flow direction $P$, was $71 \mathrm{~mm}$, the one in the transverse direction $T$, was $82 \mathrm{~mm}$ and the tube diameter $D$, was $31.8 \mathrm{~mm}$. This arrangement of tubes has been used in an actual heat exchanger of a power station. The half cylinders were installed to reduce the effect of both sides of the walls of the test section. The blockage of tube banks was 38.2 percent of the cross sectional area at the test section.

The freestream velocity ranged from 5 to $25 \mathrm{~m} / \mathrm{s}$ at the test section inlet. Reynolds numbers, based on diameter $D$ and the freestream velocity $U_{\infty}$, ranged from $1.1 \times 10^{4}$ to $5.5 \times 10^{4}$. The incoming flow from the nozzle was spatially uniform at the test section inlet and freestream turbulence

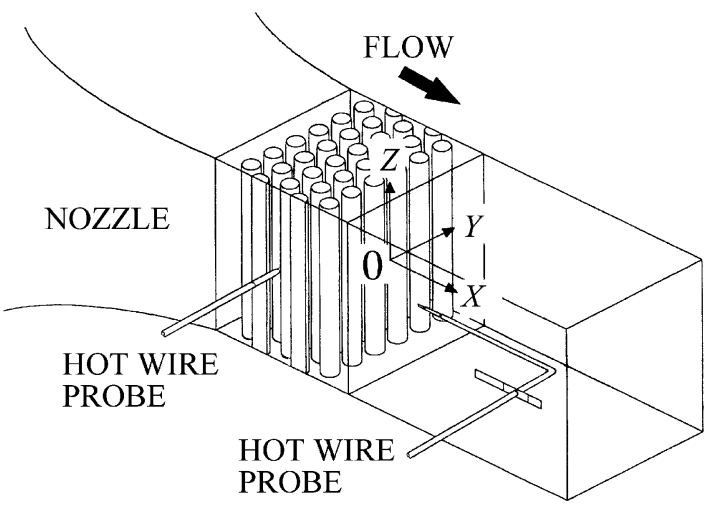

Fig. 1 Experimental apparatus and coordinate axes level was less than 0.52 percent at a freestream velocity range from 5 to $25 \mathrm{~m} / \mathrm{s}$. And no peak of spectrum of velocity fluctuation at the test section without tube banks was formed at this velocity range. The gap velocity was defined by $U_{g}=T U_{\infty} /(T-D)$.

Mean velocity and the velocity fluctuation in the wake of the tubes were measured by using two I-type hot-wire sensors, with tungsten wires of $5 \mu \mathrm{m}$ in diameter and $1.25 \mathrm{~mm}$ in sensor length. The hot-wire sensors were directed in parallel with the span ( $Z$-axis) direction to measure the velocity fluctuation due to vortex shedding from the tubes. One of the hot-wire sensors was traversed and fixed at a pre-determined location in the wake of the tube banks. The characteristics of flow, such as velocity distribution of mean flow and turbulence intensity, and the spectrum of the velocity fluctuation were measured on the $X-Y$ plane at different positions in the tube banks. The coefficient of velocity fluctuation was defined as the ratio of the intensity $u^{\prime}$, i.e. the standard deviation of velocity fluctuation, to the main flow velocity $U_{\infty}$, i.e., $u^{\prime} / U_{\infty}$.

The other hot-wire probe was installed when the cross correlation between the velocity fluctuations at two different locations was measured. The outputs from these hot-wire anemometers were automatically sampled by a computer and a FFT analyzer and then the statistical parameters were calculated.

When a hot-wire probe was installed in the tube banks, its blockage was 0.94 percent of the cross sectional area at the cross section of the tube banks. Thus, the influence on the flow system of setting the probe in the test section could be ignored even in the tube banks.

\section{Results and Discussion}

\subsection{Acoustic resonance of the duct}

The resonant frequency in the $Y$-direction of the duct is given by

$$
f=\frac{n a}{2 \ell}
$$

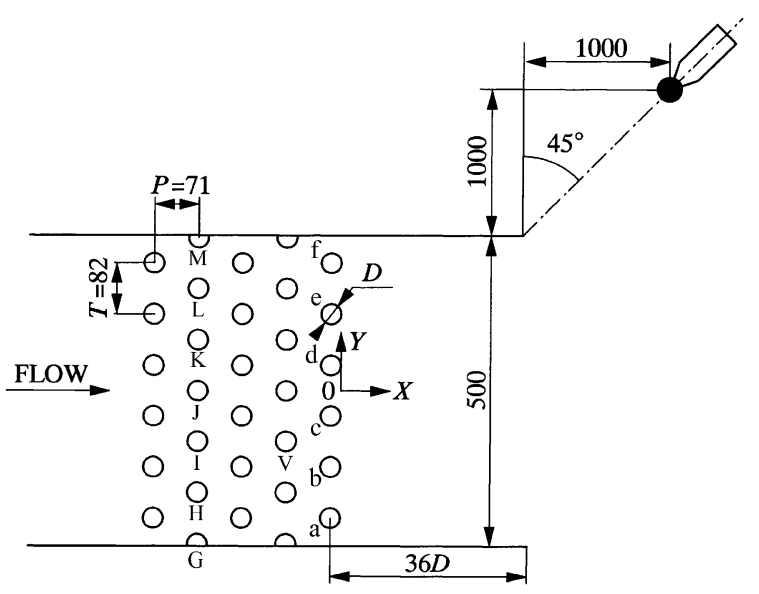

Fig. 2 Arrangement of tube banks 
where $a$ is the sound velocity, $\ell$ the width of the duct, and $n$ the number of transverse standing waves in the duct. Natural resonant frequencies in the $Y$-direction of the duct are $341.1 \mathrm{~Hz}(n=1), 682.2 \mathrm{~Hz}(n=2), \ldots$, when the duct width is $500 \mathrm{~mm}$ and the temperature of the flow $t$ is $16^{\circ} \mathrm{C}$. The error for the resonant frequency was estimated to be about $5 \mathrm{~Hz}$ because the flow temperature changed from 8 to $16^{\circ} \mathrm{C}$ in the experimental condition.

It is generally known that the sound intensity induced by vortex shedding is proportional to the velocity raised to the sixth power without acoustic resonance ${ }^{(24)}$. However, if acoustic resonance is generated at the tube banks, a strong increase of the sound intensity which is not proportional to the gap velocity raised to the sixth power is observed. And the line spectrum which has a single high peak at the resonant frequency and a lock-in phenomenon is observed. Therefore, we have judged that it was an acoustic resonant phenomenon for the following reasons; (1) The sound intensity which was not proportional to the gap velocity raised to the sixth power was observed, (2) A single high peak at the resonant frequency like a line spectrum was formed in the spectrum of velocity fluctuation,

(3) A lock-in phenomenon was observed.

\subsection{Vortex shedding characteristics without acous- tic resonance}

The velocity fluctuation was measured where the freestream velocity was $10 \mathrm{~m} / \mathrm{s}$. Figure 3 (a) - (e) show the spectral distributions measured at points $\mathrm{A}, \mathrm{B}, \mathrm{C}, \mathrm{D}$, and E. Two peaks form at 158.8 and $117.5 \mathrm{~Hz}$ in the spectrum at point $\mathrm{A}$ as shown in Fig. 3 (a). If $117.5 \mathrm{~Hz}$ is the fundamental frequency of the velocity fluctuation, it is clear that $158.8 \mathrm{~Hz}$ is not its harmonic. At point $\mathrm{B}$, downstream of the second row, the amplitude of the $158.8 \mathrm{~Hz}$ component becomes the strongest level and the other one, $117.5 \mathrm{~Hz}$, is still weak and broad. The existence of two peaks in these spectrums suggests the existence of two types of periodic phenomenon in the tube banks. At points $\mathrm{C}$ and $\mathrm{D}$, the peak level at $158.8 \mathrm{~Hz}$ decreases as shown in Fig. 3 (c) and (d). At point E, in the wake of the tube banks, these components become weak.

The coherence function and the phase delay of the velocity fluctuations were measured by setting the fixed reference probe at point $\mathrm{B}, Y=24 \mathrm{~mm}$, and the other probe at different locations along the $Y$-direction through point B downstream of the second row of tube banks. Figure 4 shows the measured phase delay of velocity fluctuations at $158.8 \mathrm{~Hz}$ between the two points at the gap velocity of $U_{g}=16.3 \mathrm{~m} / \mathrm{s}$. It was noticed that the velocity fluctuations of the two points on both sides of the wake of a single tube were out of phase with each other, which was the typical characteristic of Karman vortex shedding. But the velocity fluctuations on the same side of the wakes of all the tubes of the second row were in phase. The similar results were obtained also for $117.5 \mathrm{~Hz}$ and $97 \mathrm{~Hz}$ component.
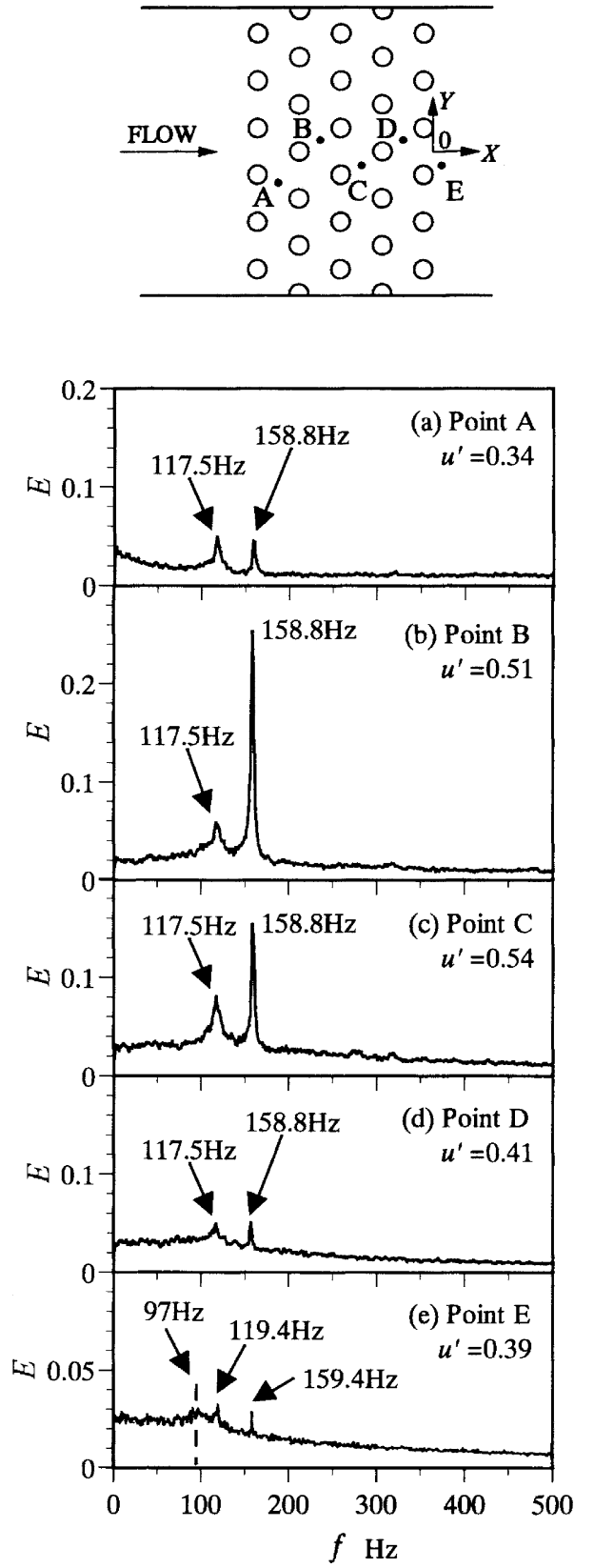

Fig. 3 Spectral distributions of $u_{\max }^{\prime}$ in tube banks $\left(U_{\infty}=\right.$ $10 \mathrm{~m} / \mathrm{s}, U_{g}=16.3 \mathrm{~m} / \mathrm{s}$, No resonance, Frequency resolution $\Delta f=0.625 \mathrm{~Hz}$ )

Figure 5 shows the distribution of the coherence function $C_{s}$ at the vortex shedding frequency $158.8 \mathrm{~Hz}$ in the $Y$-direction under the same flow condition as in Fig. 4. The maximum value for the coherence function appears around the reference point, which is $Y=24 \mathrm{~mm}$ and $Z=$ $0 \mathrm{~mm}$. The coherence decreased gradually as the distance from the reference hot-wire sensors increased.

Figure 6 shows the peak frequencies of the spectrum of velocity fluctuation, which were measured at point $B$ shown in Fig. 3, and plotted against the mean gap velocity. It was clear that the peak frequencies of the spectrum increased in proportion to the gap velocity. The Strouhal 


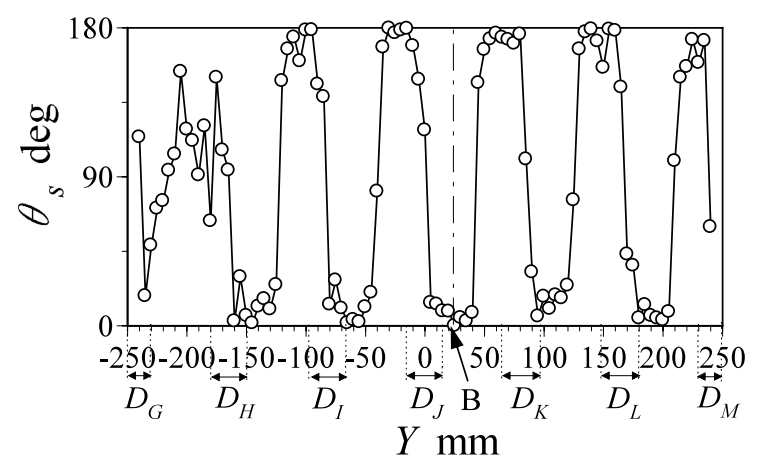

Fig. 4 Phase delay of velocity fluctuations at $158.8 \mathrm{~Hz}\left(S_{t}=\right.$ 0.29 ) between two points in the near wake of the second row of the tube banks $\left(U_{\infty}=10 \mathrm{~m} / \mathrm{s}, U_{g}=16.3 \mathrm{~m} / \mathrm{s}\right.$, No resonance)

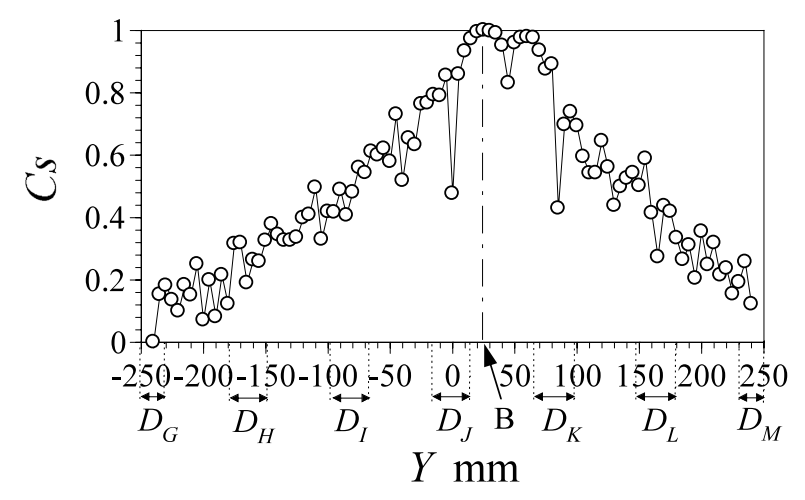

Fig. 5 Coherence between velocity fluctuations at two points in the wake of the second row in the tube banks $\left(f_{s}=\right.$ $158.8 \mathrm{~Hz}, S_{t}=0.29, U_{\infty}=10 \mathrm{~m} / \mathrm{s}, U_{g}=16.3 \mathrm{~m} / \mathrm{s}$, No resonance)

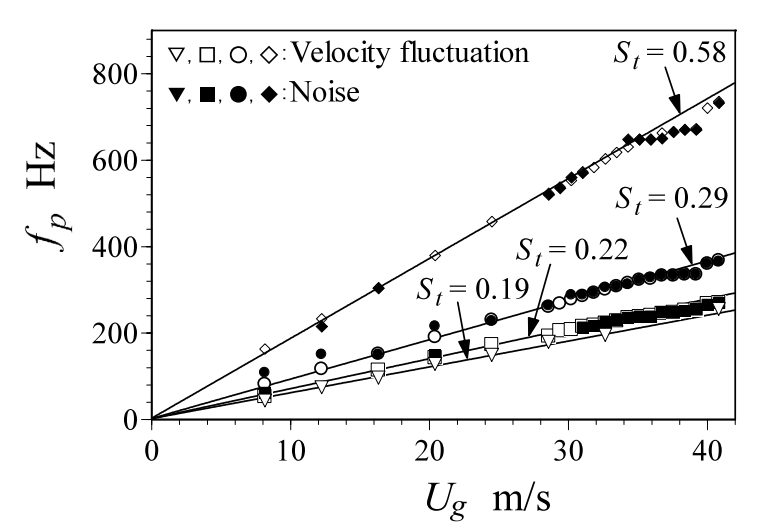

Fig. 6 Variation of peak frequency against the gap velocity

number is defined by

$$
S_{t}=\frac{f_{s} D}{U_{g}}
$$

where $f_{s}$ is the measured value of the peak frequency, $D$ the tube diameter, and $U_{g}$ the gap velocity. The frequency components, $158.8,117.5$, and $97 \mathrm{~Hz}$, correspond to the Strouhal number $S_{t}$ for $0.29,0.22,0.19$, respectively.

In order to clarify the relation between the vortex shedding phenomena with the frequencies of 158.8, 117.5,

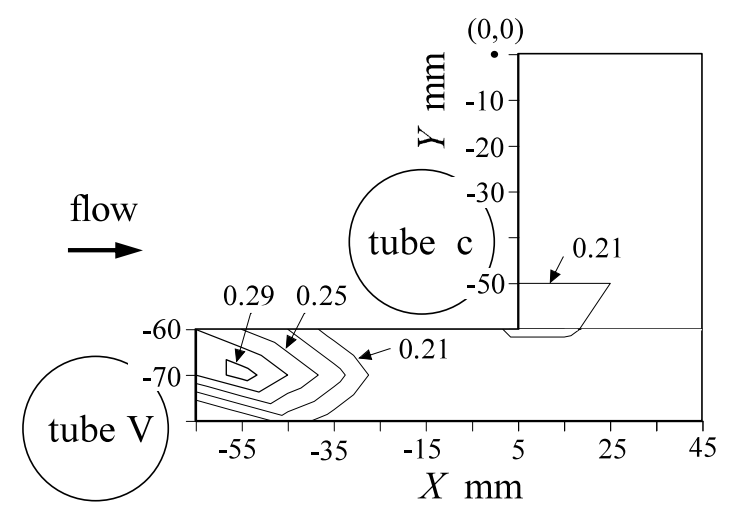

(a) $158.8 \mathrm{~Hz}$ component $\left(S_{t}=0.29\right)$

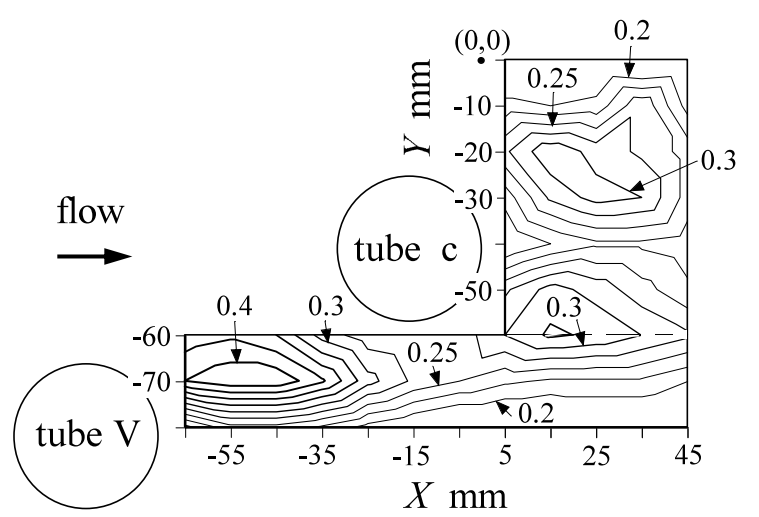

(b) $117.5 \mathrm{~Hz}$ component $\left(S_{t}=0.22\right)$

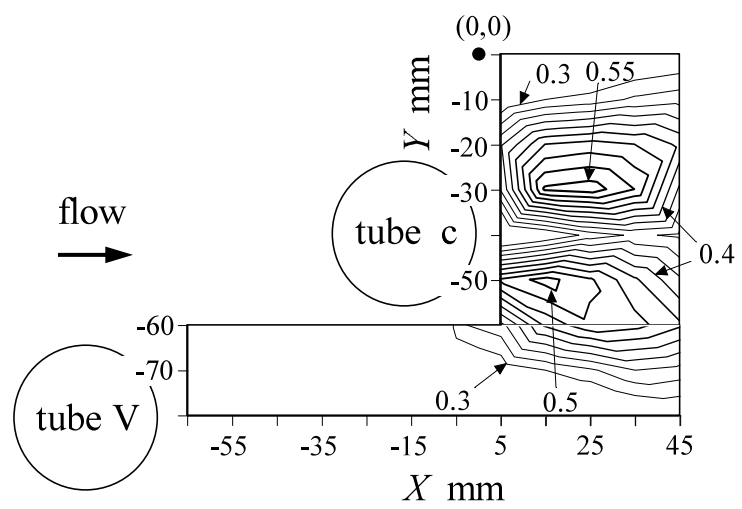

(c) $97.0 \mathrm{~Hz}$ component $\left(S_{t}=0.19\right)$

Fig. 7 Contour map of partial overall value around the last row of the tube banks $\left(U_{\infty}=10 \mathrm{~m} / \mathrm{s}, U_{g}=16.3 \mathrm{~m} / \mathrm{s}\right.$, No resonance)

and $97 \mathrm{~Hz}$, the velocity fluctuation around the last row of the tube banks was measured. Figure 7 (a) and (b) show the contour maps of the partial overall level of the discrete peak, which includes the power in the frequency band from $\left(f_{p}-5\right) \mathrm{Hz}$ to $\left(f_{p}+5\right) \mathrm{Hz}$ in the spectrum of velocity fluctuation measured in the area just downstream of the last row of the tube banks, where $f_{p}$ is the peak frequency in the spectrum. Figure 7 (c) is the result of the frequency band from $\left(f_{p}-10\right) \mathrm{Hz}$ to $\left(f_{p}+10\right) \mathrm{Hz}$, because the peak at $f_{p}=97.0 \mathrm{~Hz}$ is weak and broad. The numeral in Fig. 7 shows the amplitude of velocity fluctuation in each 
frequency band at $f_{p}=158.8 \mathrm{~Hz}$ in Fig. 7 (a), $117.5 \mathrm{~Hz}$ in Fig. 7 (b), and $97.0 \mathrm{~Hz}$ in Fig. 7 (c), respectively. From Fig. 7 (a) - (c), it was noticed that the velocity fluctuation of the 158.8 and $117.5 \mathrm{~Hz}$ components were distributed downstream of the fourth row of the tube banks and that of 117.5 and $97.0 \mathrm{~Hz}$ existed in the wake of the tube banks. And the velocity fluctuation of 158.8 and $117.5 \mathrm{~Hz}$ components alternately and irregularly occur, i.e., if one component occurs, the other one stops. Detailed account of this point is given in section 3.5. The data just behind the circular cylinder was not used when we considered the characteristics of velocity fluctuation from the results of present experiment, because the results obtained by using hot-wire sensors cannot be confided.

By the way, it is generally known that Karman vortices are formed in the wake of a circular cylinder. We measured the intensity and the spectrum of velocity fluctuation in the wake of a circular cylinder ${ }^{(25)}$. As a result, there were two regions in which the velocity fluctuation was intense on the both sides just downstream of a circular cylinder. A single high peak was found in the spectrum at the intense velocity fluctuation point. The Strouhal number calculated by using this peak frequency was about 0.2 . The phase delay between the velocity fluctuations of two points of the intense velocity fluctuation on the both sides just downstream of a circular cylinder was 180 degree. These characteristics of Karman vortices agree well with the results of the tube banks for present experiment.

From the above discussion, it was concluded that three types of Karman vortices shedding with the frequencies of $158.8 \mathrm{~Hz}\left(S_{t}=0.29\right), 117.5 \mathrm{~Hz}\left(S_{t}=0.22\right)$, and $97.0 \mathrm{~Hz}\left(S_{t}=0.19\right)$ were formed around the tube banks. The vortices of $S_{t}=0.29$ were generated inside of the tube banks, $S_{t}=0.19$ was in the wake of the last row of tube banks, and $S_{t}=0.22$ was in both regions.

\subsection{Comparison of Strouhal number map}

It is generally known that the Strouhal number varies with the pitch ratio of the tube arrangements. $\mathrm{Chen}^{(7)}$, Fitz-hugh ${ }^{(26)}$ and Weaver ${ }^{(11)}$ constructed design maps of Strouhal numbers for staggered tube banks. In order to verify the results in the present experiment, the Strouhal number maps were compared with the Strouhal number calculated by using the measured values of the vortex frequency and the gap velocity.

The Strouhal number map proposed by Fitz-hugh ${ }^{(26)}$ and $\mathrm{Chen}^{(7)}$ are most often used to estimate the vortex shedding frequency at the design stage of the heat exchanger. The Strouhal number is given to be about 0.23 by Fitz-hugh's map in the present test arrangement, $T / D=$ $2.58, P / D=2.23$ as shown in Fig. 8. Strouhal numbers calculated by the measured values of the mean gap velocity and the diameter are $0.29,0.22$, and 0.19 in the present experiment. These Strouhal numbers are expressed as $S_{t 3}, S_{t 2}, S_{t 1}$, respectively, in this section. The measured

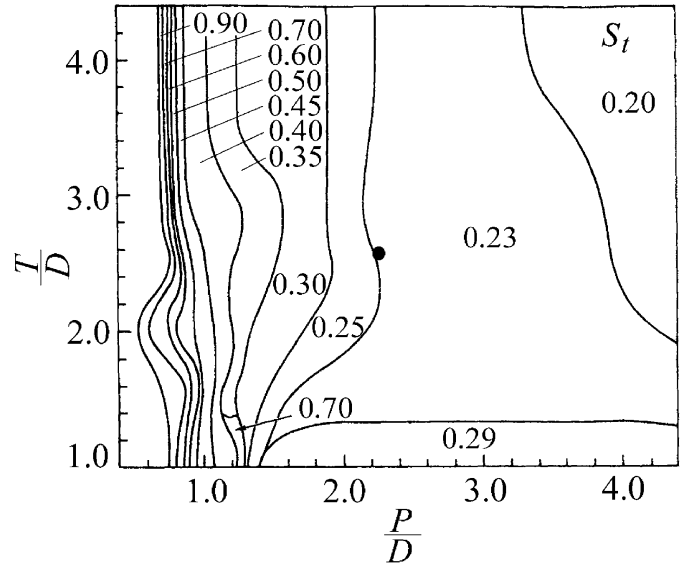

Fig. 8 Fitz-hugh's Strouhal number map

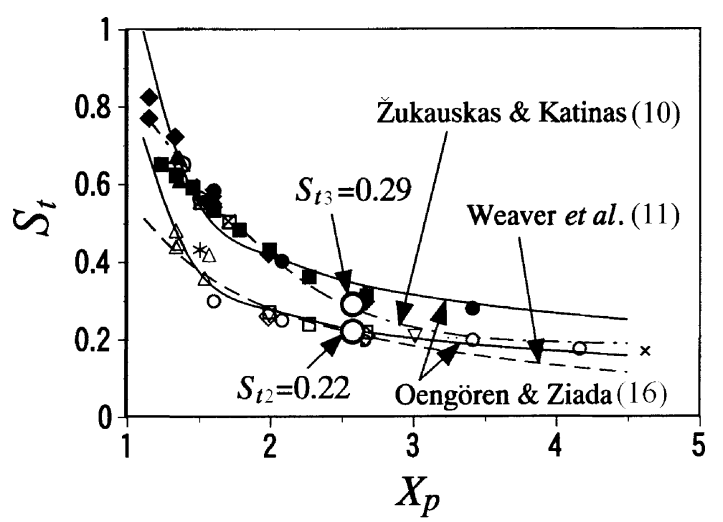

$S_{12} \quad S_{13}$

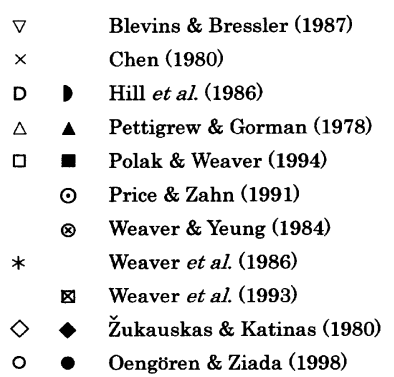

Fig. 9 Strouhal number map in normal triangle tube banks ${ }^{(16)}$

Strouhal number $S_{t 2}=0.22$ agrees well with the Strouhal number of 0.23 given by Fitz-hugh's map. This means that the vortex shedding frequency in tube banks can be estimated by using Fitz-hugh's map for bare tube banks. Another Strouhal number map for staggered tube banks has been proposed by Chen. This map gives the value 0.22 , which agrees well with the present value 0.22 . Other Strouhal numbers $S_{t 3}=0.29$ and $S_{t 1}=0.19$, however, cannot be obtained from the maps constructed by Fitz-hugh and Chen.

Strouhal number map for normal triangle tube banks has been proposed as a function of the spacing ratio $X_{p}$ $(=T / D)$ by Žukauskas \& Katinas $^{(10)}$, Weaver et al. ${ }^{(11)}$, Oengören \& Ziada ${ }^{(16)}$ as shown in Fig. 9. For $X_{p}=2.58$ 
in the present experimental condition, this map gave a Strouhal number of about 0.22 from the lower lines for the low frequency component, which was expressed by white marks and given by Weaver et al. ${ }^{(11)}$, Oengören \& Ziada $^{(16)}$ as shown in Fig. 9. Another Strouhal number was given as approximately 0.30 from the line of the high frequency component by Žukauskas \& Katinas $^{(10)}$ as also shown in Fig. 9. There was agreement with the measured Strouhal numbers $S_{t 2}=0.22$ and $S_{t 3}=0.29$ in the present experiment. However, Strouhal number $S_{t 1}=0.19$ cannot be obtained from this map.

\section{4 The relation between the periodic velocity fluc- tuation and acoustic resonance}

In order to clarify the relation between the periodic velocity fluctuation of vortex shedding and acoustic resonance, the velocity fluctuation and the sound pressure levels (SPL) of noise were measured. The SPL of noise was measured by a microphone mounted at the outside of the test section shown in Fig. 2. The peak frequencies $f_{p}$ are shown as a function of the mean gap velocity, $U_{g}$, in Fig. 6. The $f_{p}$ of noise is expressed by solid symbols and that of the velocity fluctuation by open symbols. It was clear that the peak frequencies of velocity fluctuations coincided well with that of the noise.

Variation in the SPL at the peak frequency and the partial overall value of the velocity fluctuation at point B in Fig. 3 were plotted against the gap velocity $U_{g}$ in Fig. 10. The partial overall value was defined as the power in the frequency band from $\left(f_{p}-5\right) \mathrm{Hz}$ to $\left(f_{p}+5\right) \mathrm{Hz}$ in the spectrum of velocity fluctuation, where $f_{p}$ is the peak frequency in the spectrum.

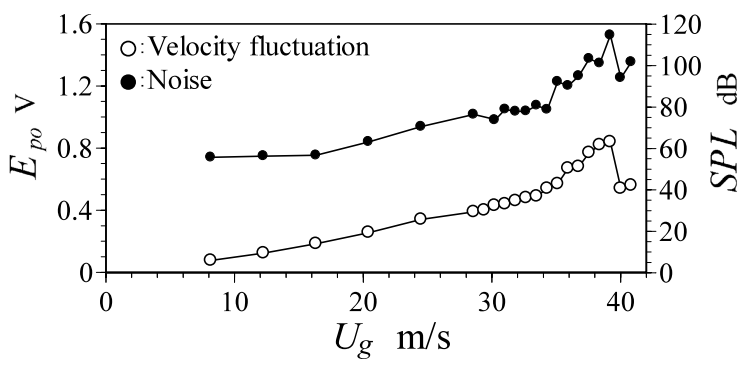

(a) $S_{t}=0.29$

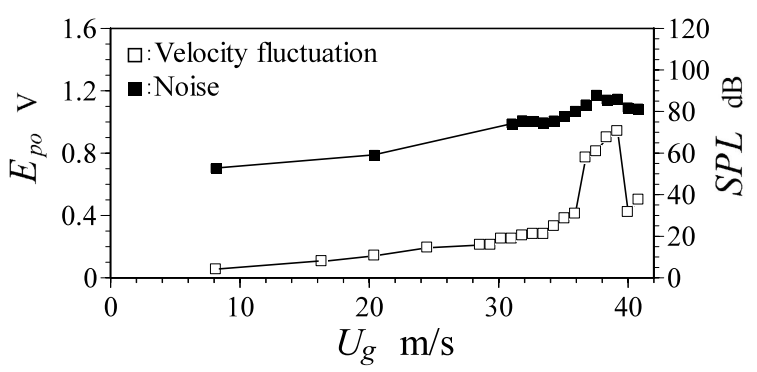

(b) $S_{t}=0.22$

Fig. 10 Variation of sound pressure level and partial overall value against gap velocity $U_{g}$
In Fig. 10 (a), the SPL and the partial overall value of the $S_{t}=0.29$ component were plotted against $U_{g}$. Both of them increased gradually up to a gap velocity about $35.0 \mathrm{~m} / \mathrm{s}$. The $S_{t}=0.29$ component includes the values of natural resonant frequency $342.5 \mathrm{~Hz}$ at the velocity range of $35.0-40.0 \mathrm{~m} / \mathrm{s}$. At the velocity of $35.0 \mathrm{~m} / \mathrm{s}$, acoustic resonance was initiated. Under this flow condition, the vortex shedding frequency coincided with the fundamental natural frequency $342.5 \mathrm{~Hz}$ in the transverse direction of the duct. Furthermore, the vortex shedding was locked in the resonant frequency of the duct system in the velocity range of $35.0-40.0 \mathrm{~m} / \mathrm{s}$. Within this range, the SPL for $S_{t}=0.29$ increased rapidly until it reached the maximum level of $115 \mathrm{~dB}$ at $U_{g}=39.2 \mathrm{~m} / \mathrm{s}$. The enhancement of the partial overall value of velocity fluctuation was also observed.

In Fig. 10 (b), a similar relation to Fig. 11 (a) for the $S_{t}=0.22$ component was plotted. Even though the acoustic resonance of the fundamental natural frequency
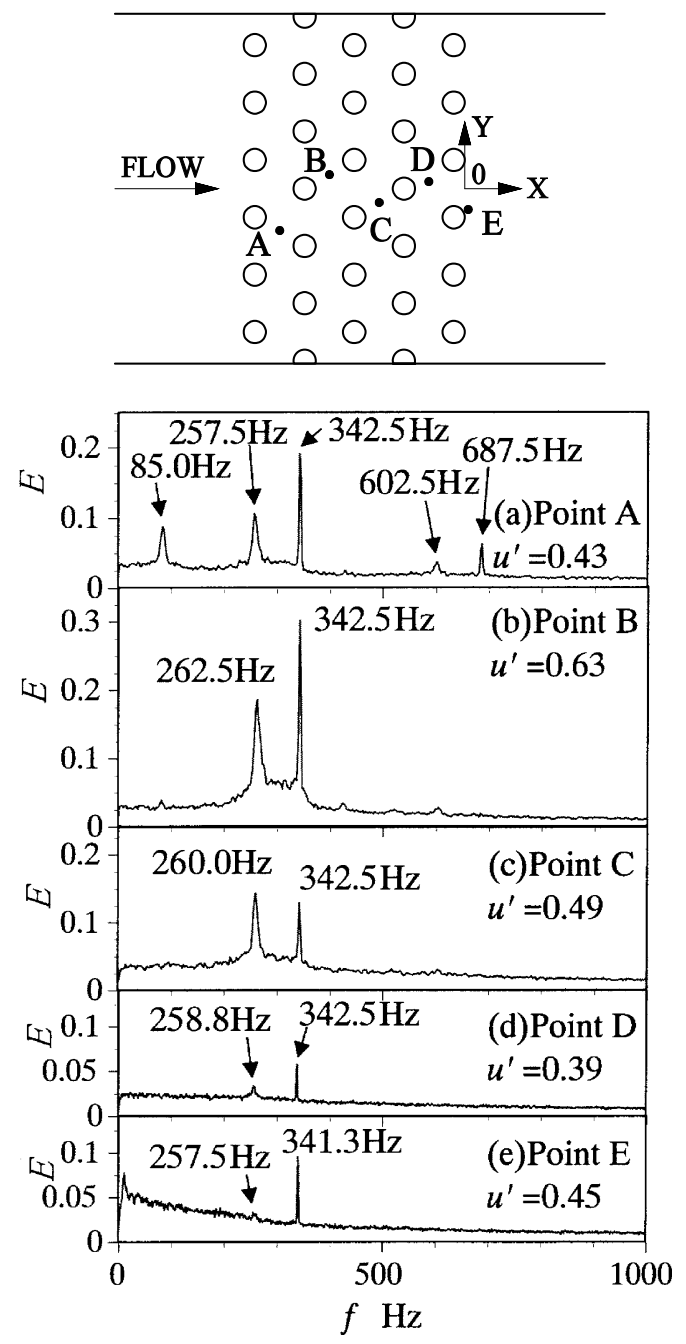

Fig. 11 Spectral distributions of $u_{\max }^{\prime}$ in tube banks in the resonant case $\left(U_{\infty}=24.0 \mathrm{~m} / \mathrm{s}, U_{g}=39.2 \mathrm{~m} / \mathrm{s}\right.$, Resonant case, Frequency resolution $\Delta f=1.25 \mathrm{~Hz}$ ) 
$342.5 \mathrm{~Hz}$ in the transverse direction of the duct was excited by the vortex shedding of $S_{t}=0.29$, the noise of the $S_{t}=0.22(262.5 \mathrm{~Hz})$ component was not excited. However, a strong increase of the partial overall value of $S_{t}=$ 0.22 was observed in the velocity fluctuation in the gap velocity range of $35.0-40.0 \mathrm{~m} / \mathrm{s}$. Because every three cycles of the vortices at $262.5 \mathrm{~Hz}$ was excited by the acoustic resonance at $342.5 \mathrm{~Hz}$. Detailed account of this point is given in section 3.5.

From the above discussion, it was concluded that acoustic resonance was generated when the vortex shedding frequency of $S_{t}=0.29$ coincided with the fundamental natural frequency $342.5 \mathrm{~Hz}$ in the transverse direction at a velocity of $35.0-40.0 \mathrm{~m} / \mathrm{s}$.

\subsection{Vortex shedding characteristics with acoustic resonance}

When the acoustic resonance at the fundamental natural frequency $342.5 \mathrm{~Hz}$ was excited in the transverse direction of the duct by the vortex shedding of $S_{t}=0.29$, the velocity fluctuation in the tube banks was measured. Figure 11(a)-(e) show the spectral distributions measured respectively at points $\mathrm{A}, \mathrm{B}, \mathrm{C}, \mathrm{D}$, and $\mathrm{E}$ shown in the figure above Fig. 11 (a). Two high peaks were found at $342.5 \mathrm{~Hz}$ $\left(S_{t}=0.29\right)$ and about $262.5 \mathrm{~Hz}\left(S_{t}=0.22\right)$ in any spectral distributions, which suggested the existence of two periodic phenomena of different frequencies in the tube banks. It was clear that $342.5 \mathrm{~Hz}$ of the velocity fluctuation was not the harmonic of $262.5 \mathrm{~Hz}$. The amplitude and periodicity of the $342.5 \mathrm{~Hz}$ component became the most intense at location B downstream of the second row of banks. At points $C$ and D in Fig. 11 (c) and (d), respectively, the peak levels decreased. At point $\mathrm{E}$, in the wake of the tube banks, the velocity fluctuation of the $342.5 \mathrm{~Hz}$ component was observed though it was weak. Thus, the sound pressure fluctuation under the resonance condition shifted the vortex shedding frequency in the wake of tube banks to the natural resonant frequency of $342.5 \mathrm{~Hz}$.

Figure 12 (a) and (b) show the changes with time of the respective amplitudes of $342.5 \mathrm{~Hz}$ and $262.5 \mathrm{~Hz}$ frequency components of the velocity fluctuation at point $\mathrm{B}$, which were analyzed simultaneously by two bandpass filters. It was clearly observed that when the amplitude of the $342.5 \mathrm{~Hz}$ component was large, the amplitude of the $262.5 \mathrm{~Hz}$ component became small, and vice versa. This means that those two components of velocity fluctuation alternately and irregularly occur, i.e., if one component occurs, the other one stops. Figure 12 (c) is enlarged view of Fig. 12 (a) and (b). It was clearly observed that three cycles at $262.5 \mathrm{~Hz}$ agreed well with four cycles at resonant frequency of $342.5 \mathrm{~Hz}$, because the vortex shedding frequency at $262.5 \mathrm{~Hz}$ was about $3 / 4$ times the resonant frequency at $342.5 \mathrm{~Hz}$. This means that every three cycles of the vortices at $262.5 \mathrm{~Hz}$ was excited by the acoustic resonance at $342.5 \mathrm{~Hz}$.

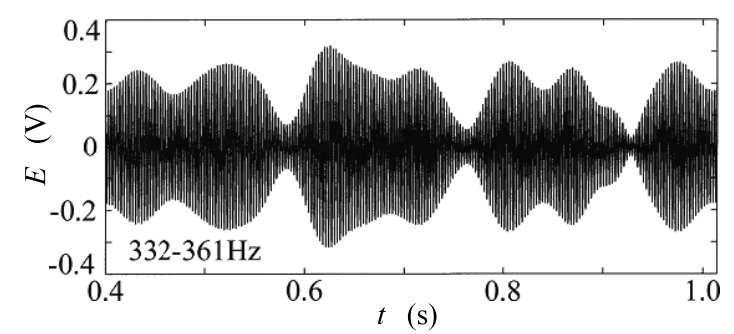

(a) $342.5 \mathrm{~Hz}$ component $\left(S_{t}=0.29\right)$

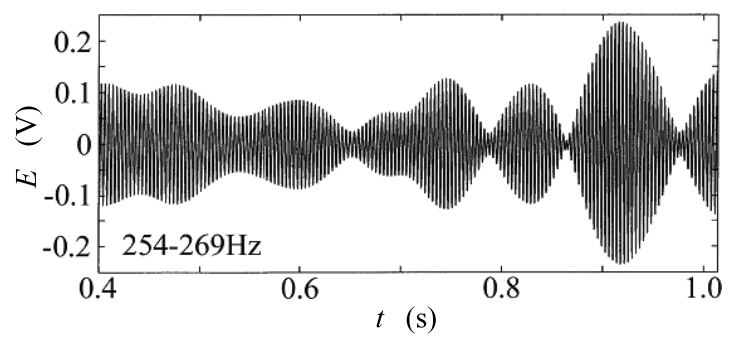

(b) $260 \mathrm{~Hz}$ component $\left(S_{t}=0.22\right)$

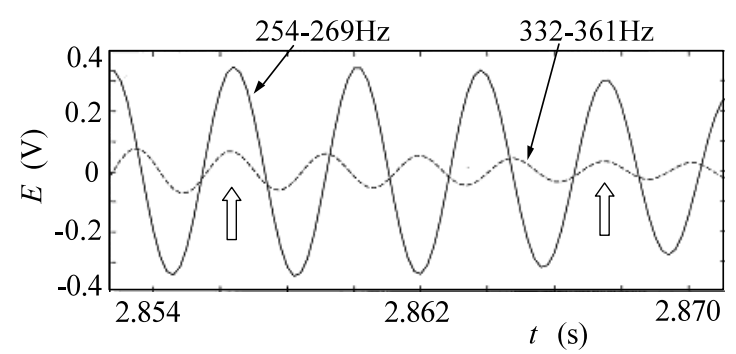

(c) Enlarged view

Fig. 12 Time variation of amplitude of two peak frequency components $\left(U_{\infty}=24.0 \mathrm{~m} / \mathrm{s}, U_{g}=39.2 \mathrm{~m} / \mathrm{s}\right.$, Resonant case)

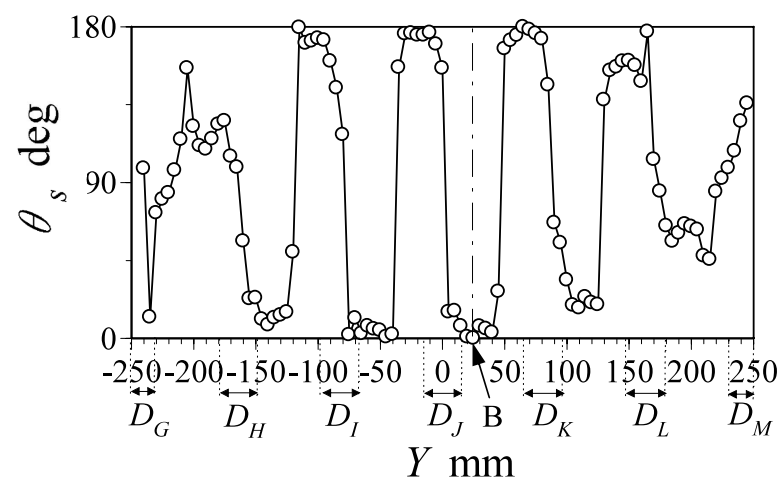

Fig. 13 Phase delay between velocity fluctuations at two points in the near wake of the second row in the tube banks $\left(f_{s}=342.5 \mathrm{~Hz}, S_{t}=0.29, U_{\infty}=24.0 \mathrm{~m} / \mathrm{s}, U_{g}=39.2 \mathrm{~m} / \mathrm{s}\right.$, Resonant case)

Under the resonant condition, the coherence function and the phase delay of velocity fluctuations were measured with the fixed probe being set at the reference point $(Y=24 \mathrm{~mm})$ and the other probe being moved along the $Y$ direction downstream of the second row of the tube banks. The results are shown in Fig. 13 for the phase delay of the velocity fluctuations of the vortex shedding frequency $342.5 \mathrm{~Hz}\left(S_{t}=0.29\right)$ component downstream of the second 
row of the tube banks at a gap velocity of $U_{g}=39.2 \mathrm{~m} / \mathrm{s}$. The velocity fluctuations at two points on both sides of the near wake of each single tube were out of phase with each other. These were alternating vortices like the Karman vortices from a single circular cylinder. The vortices on the same side of the wakes of all the tubes of the second row were in phase.

Figure 14 shows the distribution of the coherence function $C_{s}$ for the vortex shedding frequency, $342.5 \mathrm{~Hz}$ $\left(S_{t}=0.29\right)$. The coherence distributes with a high level, $0.9-1.0$, along the second row of the tubes. That is, when the acoustic resonance generated at the natural frequency $342.5 \mathrm{~Hz}$ of the duct, the correlation of vortices along the transverse direction of duct becomes intense.

Figure 15 (a) and (b) show the contour maps of the partial overall level included in the frequency band from $\left(f_{p}-5\right) \mathrm{Hz}$ to $\left(f_{p}+5\right) \mathrm{Hz}$ in the spectrum of velocity fluctuation in the area just downstream of the last row of the tube banks, where $f_{p}$ is the peak frequency in the spectrum. The numeral in Fig. 15 means the amplitude of velocity fluctuation in each frequency band at $342.5 \mathrm{~Hz}$ in Fig. 15 (a) and at $262.5 \mathrm{~Hz}$ in Fig. 15 (b). From Fig. 15, it is noticed that the vortices of $262.5 \mathrm{~Hz}\left(S_{t}=0.22\right)$ generates inside of the tube banks, $342.5 \mathrm{~Hz}\left(S_{t}=0.29\right)$ is in both regions inside and downstream side of the tube banks. By the way, the data just behind the circular cylinder was not used when we considered the vortex shedding characteristics from the results of present experiment, because the results obtained by using hot-wire sensors cannot be confided.

From the above discussion, it was concluded that two types of vortex shedding with different frequencies, mainly $342.5 \mathrm{~Hz}\left(S_{t}=0.29\right)$ and $262.5 \mathrm{~Hz}\left(S_{t}=0.22\right)$, were generated in the tube banks when the acoustic resonance generated at the natural frequency of the duct, $342.5 \mathrm{~Hz}$, at a gap velocity of $39.2 \mathrm{~m} / \mathrm{s}$. The vortices of $262.5 \mathrm{~Hz}\left(S_{t}=0.22\right)$ were limited inside of the tube banks, but $342.5 \mathrm{~Hz}\left(S_{t}=0.29\right)$ was in both regions inside and on the downstream side of the tube banks.

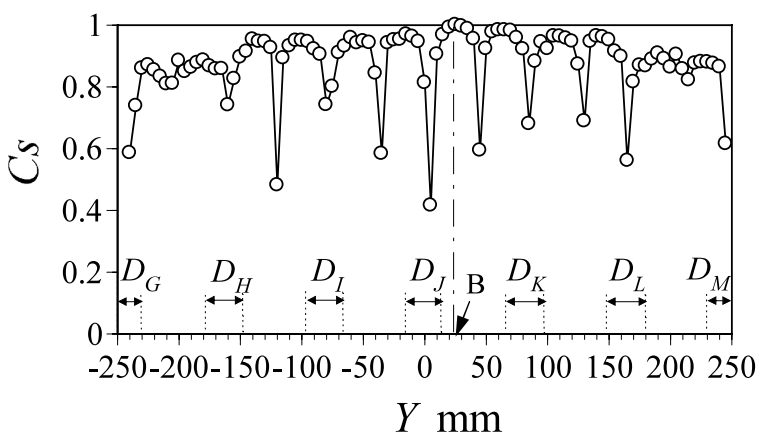

Fig. 14 Coherence of the velocity fluctuations between two points in the near wake of the second row of the tube banks $\left(f_{s}=342.5 \mathrm{~Hz}, S_{t}=0.29, U_{\infty}=24.0 \mathrm{~m} / \mathrm{s}, U_{g}=\right.$ $39.2 \mathrm{~m} / \mathrm{s}$, Resonant case)

\subsection{Effect of baffle plates on acoustic resonance}

It is known that the transverse mode of acoustic resonance can be controlled by dividing the duct width using baffle plates ${ }^{(27)-(30)}$. In the present study, the same method was attempted by setting a baffle plate as shown in Fig. 16. The three kinds of baffle plates were made from plates $3 \mathrm{~mm}$ thick, $500 \mathrm{~mm}$ in height and 142, 284, and $426 \mathrm{~mm}$ in length. The duct width was divided into two sections, 228 and $269 \mathrm{~mm}$, by installing baffle plates.

In Fig. 16, the SPL of the $S_{t 3}=0.29$ component, which was the most intense, was plotted against the gap velocity with the baffle plates. A strong increase in SPL was observed in the gap velocity range of $35.0-40.0 \mathrm{~m} / \mathrm{s}$ in cases without a baffle plate, but not with baffle plates in any cases of plate length $L=142,284$, or $426 \mathrm{~mm}$. The maximum decrease of the SPL was about $30 \mathrm{~dB}$. The transverse mode of acoustic resonance was suppressed to install the short plate, $L=142 \mathrm{~mm}$, which covered the first and second rows where the amplitude and the periodicity of the velocity fluctuation due to vortex shedding became the strongest in the tube banks.

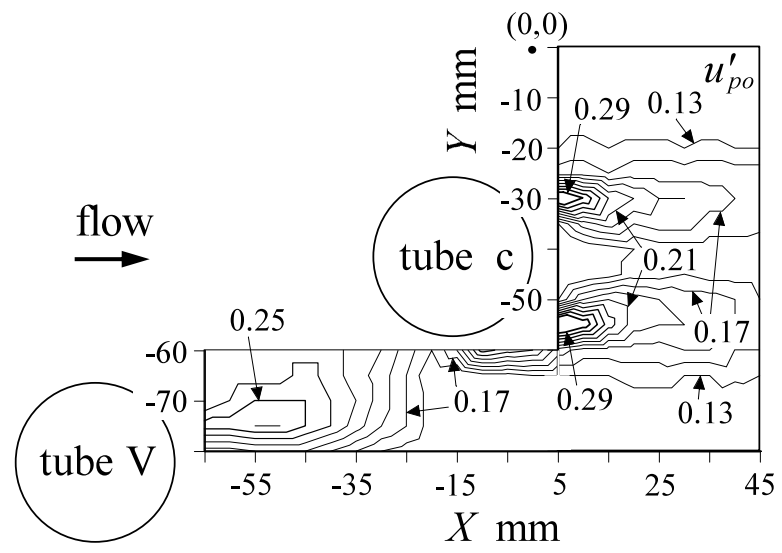

(a) $342.5 \mathrm{~Hz}$ component $\left(S_{t}=0.29\right)$

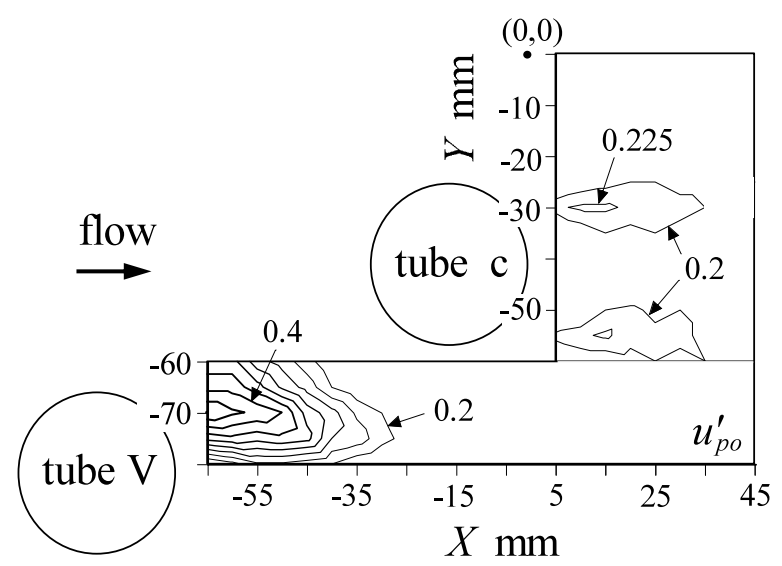

(b) $262.5 \mathrm{~Hz}$ component $\left(S_{t}=0.22\right)$

Fig. 15 Contour map of the overall value of the velocity fluctuation around the last row of the tube banks $\left(U_{\infty}=\right.$ $24.0 \mathrm{~m} / \mathrm{s}, U_{g}=39.2 \mathrm{~m} / \mathrm{s}$, Resonant case) 

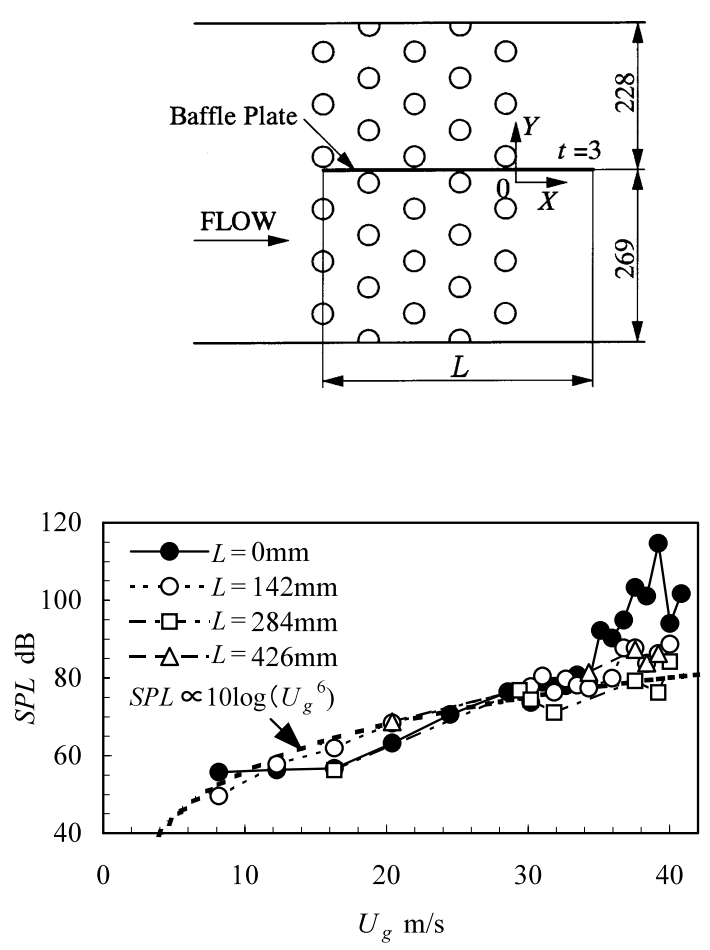

Fig. 16 Effect of baffle plate on sound pressure level $\left(S_{t}=0.29\right)$

This result meant that a short baffle plate was effective for preventing the generation of acoustic resonance of the transverse mode if it was installed at the correct place where velocity fluctuation and periodicity of vortex shedding were most intense.

\section{Conclusions}

The relationship between acoustic resonance and vortex shedding from staggered tube banks was experimentally investigated. The flow characteristics, such as the spectrum, phase, and coherence of the velocity fluctuation, were measured in the tube banks. As a result, the following conclusions were obtained.

(1) Three types of vortex shedding with different Strouhal numbers, $0.29,0.22$, and 0.19 , occurred at the same flow condition in cases without acoustic resonance. The vortex shedding of $S_{t}=0.29$ was generated inside the tube banks, $S_{t}=0.19$ was in the wake of the last row of the tube banks, and $S_{t}=0.22$ was in both regions.

(2) When the acoustic resonance of the transverse mode generated was at the natural frequency $342.5 \mathrm{~Hz}$, two types of vortex shedding with different frequencies, $342.5 \mathrm{~Hz}$ and approximately $262.5 \mathrm{~Hz}$, occurred in the tube banks. Their Strouhal numbers were 0.29 and 0.22 , respectively. The vortices of $262.5 \mathrm{~Hz}\left(S_{t}=0.22\right)$ generates inside of the tube banks, $342.5 \mathrm{~Hz}\left(S_{t}=0.29\right)$ is in both regions inside and downstream side of the tube banks.

(3) As the vortex shedding frequency approached the resonant frequency of the duct by increasing main flow velocity, acoustic resonance was generated. This resonance strongly enhanced the periodicity and amplitude of the velocity fluctuation of vortex shedding by increasing the transverse correlation scale of the vortex, locking the shedding frequency in the natural resonant frequency and synchronizing the vortex shedding pattern in the tube banks.

( 4 ) It was clarified that if the amplitude of the velocity fluctuation of the $S_{t}=0.29$ component becomes large, the amplitude of $S_{t}=0.22$ component becomes small, and vice versa. The vortices of the $S_{t}=0.29$ and 0.22 components alternately and irregularly originate, i.e., if one component originates, the other one stops.

(5) Short baffle plate were effective in preventing acoustic resonance of the transverse mode from generating if it was installed in the space where the velocity fluctuation and the periodicity of vortex shedding were most intense.

\section{References}

( 1 ) Païdoussis, M.P., A Review of Flow-Induced Vibrations in Reactors and Reactor Components, J. Nuclear Eng. Design, Vol.74 (1982), pp.31-60.

( 2 ) Pettigrew, M.J. and Taylor, C.E., Vibration Analysis of Shell-and Tube Heat Exchangers: An Overview Part1: Flow, Damping, Fluidelastic Instability, J. Fluids Struct., Vol.18 (2003), pp.469-483.

( 3 ) Pettigrew, M.J. and Taylor, C.E., Vibration Analysis of Shell-and Tube Heat Exchangers: An Overview Part2: Vibration Response, Fretting-Wear, Guidelines, J. Fluids Struct., Vol.18 (2003), pp.485-500.

( 4 ) Weaver, D.S. and Fitzpatrick, J.A., A Review of CrossFlow Induced Vibration in Heat Exchanger Tube Arrays, J. Fluids Struct., Vol.7 (1988), pp.73-93.

( 5 ) Chen, S.S., Guidelines for the Instability Flow Velocity of Tube Arrays in Crossflow, J. Sound Vib., Vol.93 (1984), pp.439-455.

( 6 ) Owen, P.R., Buffeting Excitation of Boiler Tube Vibration, J. Mech. Eng. Sci., Vol.7 (1965), pp.431-439.

( 7 ) Chen, Y.N., Flow-Induced Vibration and Noise in Tube-Bank Heat Exchangers Due to Von Karman Streets, Trans. ASME, J. Eng. Ind., Ser. B, Vol.94 (1968), pp.134-146.

( 8 ) Weaver, D.S., Vortex Shedding and Acoustic Resonance in Heat Exchanger Tube Arrays, Technology for the 90's, ASME, (1993), pp.776-810.

(9) Ziada, S. and Oengören, A., Vortex Shedding in an inLine Tube Bundle with Large Tube Spacings, J. Fluids Struct., Vol.7 (1993), pp.661-687.

(10) Žukauskas, A. and Katinas, V., Flow-Induced Vibration in Heat Exchanger Tube Banks, Practical Experiences with Flow-Induced Vibrations, (1980), pp.188-196.

(11) Weaver, D.S., Fitzpatrick, J.A. and Elkashlan, M., Strouhal Numbers for Heat Exchanger Tube Arrays in Cross Flow, Flow Induced Vibration 1986, PVPVol.104 (1986), pp.193-200.

(12) Ziada, S., Oengören, A. and Buhlmann, E.T., On Acoustical Resonance in Tube Arrays - Part I: Experiments, J. Fluids Struct., Vol.3 (1989), pp.293-314.

(13) Price, S.J. and Zahn, M.L., Fluid Elastic Behavior of a 
Normal Array Subject to Cross-Flow, J. Fluids Struct., Vol.5 (1991), pp.259-278.

(14) Weaver, D.S., Lian, H.Y. and Huang, X.Y., Vortex Shedding in Rotated Square Tube Arrays, J. Fluids Struct., Vol.7 (1993), pp.107-121.

(15) Polak, D.R. and Weaver, D.S., Vortex Shedding in Normal Triangular Tube Arrays, J. Fluids Struct., Vol.9 (1995), pp.1-17.

(16) Oengören, A. and Ziada, S., An In-Depth Study of Vortex Shedding, Acoustic Resonance and Turbulent Forces in Normal Triangle Tube Arrays, J. Fluids Struct., Vol.12 (1998), pp.717-758.

(17) Blevins, R.D., The Effect of Sound on Vortex Shedding from Cylinders, J. Fluid Mech., Vol.161 (1985), pp.217-237.

(18) Richardson, P.D., Effects of Sound and Vibration on Heat Transfer, Applied Mechanics Reviews, Vol.20 (1967), pp.201-217.

(19) Peterka, J.A. and Richardson, P.D., Effects of Sound on Separated Flows, J. Fluid Mech., Vol.37 (1969), pp.265-287.

(20) Okamoto, S., Hirose, T. and Adachi, T., The Effect of Sound on the Vortex Shedding from a Circular Cylinder, Bull. Jpn. Soc. Mech. Eng., Vol.24, No.187 (1981), pp.45-53.

(21) Ziada, S. and Oengören, A., Vorticity Shedding and Acoustic Resonance in an in-Line Tube Bundle Part I: Vorticity Shedding, J. Fluids Struct., Vol.6 (1992), pp.271-292.

(22) Ziada, S. and Oengören, A., Vortex Shedding in an in-Line Tube Bundle with Large Tube Spacings, International Symposium on Flow-Induced Vibration and Noise, Vol.1 (1992), pp.1-28.

(23) Oengören, A. and Ziada, S., Vorticity Shedding and Acoustic Resonance in an in-Line Tube Bundle Part II: Acoustic Resonance, J. Fluids Struct., Vol.6 (1992), pp.293-309.

(24) Blevins, R.D., Flow-Induced Vibration, (1986), R.E. Krieger Publishing Company.

(25) Hamakawa, H., Fukano, T., Nishida, E. and Aragaki, M., Vortex Shedding from a Circular Cylinder with Fin, Proceeding of 7th AIAA/CEAS Aeroacoustics Conference, AIAA-2001-2215, CD-ROM, (2001).

(26) Fitz-hugh, J.S., Flow Induced Vibration in Heat Exchangers, Proc. UKAEA/NPL International Symposium on Vibration Problems in Industry, Keswick, England, Paper 427, (1973), pp.1-17.

(27) Nemoto, A. and Yamada, M., Flow-Induced Acoustic Resonance in Staggered Tube-Banks, Flow-Induced Vibration ASME, PVP-Vol.273 (1994), pp.137-152.

(28) Blevins, R.D. and Bressler, M.M., Acoustic Resonance in Heat Exchanger Tube Bundles; Part I; Prediction and Suppression of Resonance, Trans. ASME, J. Press. Vessel Technol., Vol.109 (1987), pp.282-288.

(29) Eisinger, F.L., Prevention and Cure of Flow-Induced Vibration Problems in Tubular Heat Exchangers, Trans. ASME, J. Press. Vessel Technol., Vol.102 (1980), pp.138-145.

(30) Sullivan, R.E., Francis, J.T. and Eisinger, F.L., Prevention of Acoustic Vibration in Steam Generator and Heat Exchanger Tube Banks, Flow-Induced Vibration and Transient Thermal-Hydraulics, PVP-Vol.363 (1998), pp.1-9. 